for participant bias whereby learners provide answers they believe would benefit the research team. Nonetheless, in the wider literature, there is limited evidence examining the role of open- and closed-book examinations in dentistry, and this evaluation provides further support for future directed research.

\section{Conclusion}

The COVID-19 impact on education is substantial, not only on finances for universities and educational establishments, but also on learner experiences. Dental education continues to evolve in the current climate and educators must seek to evaluate new models of assessment, including remote open-book assessment and virtual platforms instead of faceto-face assessments. Sharing best practice across dental schools is key to enable robust evidencebased examinations, which is integral to ensure learners are able to demonstrate learning outcomes to graduate as safe beginners and begin their professional career.

\section{Acknowledgements}

Selected results of this study have previously been published in the British Dental Journal.
Ethics declaration

Ethical approval was not sought after as the article involves data gathered for the purpose of service evaluation in an education institution.

\section{Conflict of interest}

None declared.

\section{References}

1. Eurboonyanun C, Wittayapairoch J, Aphinives P, Petrusa E, Gee D W, Phitayakorn R. Adaptation to Open-Book Online Examination During the COVID-19 Pandemic J Surg Educ 2021; 78: 737-739.

2. Dave M, Ariyaratnam S, Dixon C, Patel N. Open-book examinations. Br Dent J 2020; 229: 149.

3. Ramamurthy S, Meng Er H, Nadarajah V D, Pook P C K. Study on the impact of open and closed book formative examinations on pharmacy students' performance, perception, and learning approach. Curr Pharm Teach Learn 2016; 8: 364-374

4. Heijne-Penninga M, Kuks J B, Hofman W H, CohenSchotanus J. Influence of open-and closed-book tests on medical students' learning approaches. Med Educ 2008; 42: 967-974

5. Karagiannopoulou E, Milienos FS. Exploring the relationship between experienced students' preference for open-and closed-book examinations, approaches to learning and achievement. Educ Res Eval 2013; 19: 271-296.

6. Swart A J, Sutherland T. Student Perspectives of Open Book versus Closed Book Examinations a Case Study in Satellite Communication. Int J Eng Educ 2014; 30: 210-217.

7. Grace C, Begum R, Subhani S, Kopelman P, Greenhalgh T. Prevention of type 2 diabetes in British Bangladeshis: qualitative study of community, religious, and professional perspectives. BMJ 2008; DOI: 10.1136/ bmj.a1931.
8. Maykut PS, Morehouse R. Beginning Qualitative Research: A Philosophic and Practical Guide. Norfolk, Great Britain: Falmer Press, 1994

9. El Ansari W, Stock C. Is the health and wellbeing of university students associated with their academic performance? Cross sectional findings from the United Kingdom. Int J Environ Res Public Health 2010; 7: 509-527.

10. Theophilides C, Dionysiou 0. The major functions of the open-book examination at the university level: A factor analytic study. Stud Educ Eval 1996; 22: 157-170.

11. Broyles I L, Cyr P R, Korsen N. Open book tests: assessment of academic learning in clerkships. Med Teach 2005; 27: 456-462.

12. Bobby Z, Meiyappan K. "Test-enhanced" focused self-directed learning after the teaching modules in biochemistry. Biochem Mol Biol Educ 2018; 46: 472-477.

13. Lipner R S, Brossman B G, Samonte K M, Durning S J. Effect of Access to an Electronic Medical Resource on Performance Characteristics of a Certification Examination: A Randomized Controlled Trial. Ann Intern Med 2017; 167: 302-310.

14. Bloom B S, Krathwohl D R, Masia B B. Taxonomy of Educational Objectives: The Classification of Educational Goals. New York: David McKay, 1956

15. Adams N E. Bloom's taxonomy of cognitive learning objectives. J Med Libr Assoc 2015; 103: 152-153.

16. The University of Newcastle Australia. A guide for academics - open book exams. 2020. Available online at https://www.newcastle.edu.au/_data/assets/pdf file/0006/268980/0pen-Book-Exams.pdf (accessed September 2020).

17. General Dental Council. Preparing for practice. 2015. Available at https://www.gdc-uk.org/docs/defaultsource/quality-assurance/preparing-for-practice(revised-2015).pdf (accessed September 2020).

18. Anderson L W, Krathwohl D R, Airasian P W etal. (eds). A Taxonomy for Learning, Teaching, and Assessing: A Revision of Bloom's Taxonomy of Educational Objectives. Boston: Addison Wesley Longman, 2001.

\title{
Correction to: Cause for applause
}

The original article can be found online at https://www.nature.com/articles/s41415-021-3294-3

Journal's correction note:

News article Br Dent J 2021; 231: 78.

When this article was originally published, the image caption incorrectly identified the dentist featured as Dr Neil Sikka.

The journal apologises for any inconvenience caused. 